\title{
Effect of Exogenous Administration of Vitamins on Improving the Semen Quality of Crossbred Cattle Bulls
}

\author{
Kanchan* and S. S. Dhindsa \\ Department of Veterinary Physiology and Biochemistry, Guru Angad Dev Veterinary and \\ Animal Sciences University, Ludhiana - 141004, Punjab (India) \\ *Corresponding author
}

\begin{tabular}{|l|}
\hline K e y w o r d s \\
Crossbred bull, \\
Seminal parameters, \\
Vitamins, Semen \\
quality
\end{tabular}

\section{Introduction}

The major aim of the Crossbreeding project is to develop a new breed/strain of dairy cattle to develop a new breed/strain of dairy catle

\section{A B S T R A C T}

Nutritional inadequacies and nutrient imbalance especially of vitamins may lead to impairment of male reproduction and leads to poor semen quality and requires exogenous supplementation to improve semen quality and fertility of cryopreserved semen in cattle bulls. A group of eight crossbred bulls (75\% Holstein Friesian, 25\% Sahiwal, 3-5 years old) maintained at dairy farm GADVASU, Ludhiana apparently healthy showing no visual sign of testicular atrophy and reduced libido but exhibited poor semen quality i.e. (watery ejaculates with poor sperm concentration less than 500 million per ml, initial sperm motility $<60 \%$ and poor freezability). Bulls were divided into two groups ( $n=4$ in each). Group- I bulls were administered Vitamins (Vitamin A (120000 IU); Vitamin $\mathrm{D}_{3}(60000$ IU); Vitamin E (480 mg); and Nicotinamide $(30 \mathrm{mg})$ and Vitamin $\mathrm{H}(500 \mathrm{mcg})$ ) orally for consecutive seven days (INTAVITA NH oral dose $10 \mathrm{ml}$ ) in first treatment and after fifteen days of first treatment the second dose of Vitamins viz. Vitamin A (2500000 IU); Vitamin $\mathrm{D}_{3}(250000 \mathrm{IU})$; Vitamin $\mathrm{E}(1000 \mathrm{IU})$ was administered through intramuscular route (INTAVITA $10 \mathrm{ml}$, INTAS). Group II was taken as control group. Semen collection was suspended during treatment and for at least one month after post treatment. The various seminal parameters viz. volume $(\mathrm{ml})$, consistency (grade as 0-3), mass activity (graded as 0-4), sperm concentration (million/ml),initial motility $(\%)$, prefreeze motility (\%) and post thaw motility $(\%)$ were recorded before and after treatments. The data was statistically analyzed using standard t-test. The results showed significant increase in sperm concentration, mass activity, initial motility and semen acquired freezability (Prefreeze motility $60.66 \pm 1.64 \%$; post thaw motility $46.33 \pm 0.80 \%$ ) in treated group as compared to control. It is concluded that exogenous administration of vitamins has shown marked improvement in semen quality of crossbred cattle bulls and therefore, it is suggested that periodic monitoring of micronutrients supplements in diet in recommended amounts is essential to maintain the semen quality of crossbred bulls.

\begin{abstract}
by using crossbreds possessing $75 \%$ exotic inheritance as a foundation stock, followed by selective breeding, especially the identification and selection of crossbred bulls
\end{abstract}


through progeny testing under farm and field conditions. More than $75 \%$ total ejaculates are discarded due to poor initial motility even in high quality elite crossbred bulls (Chauhan et $a l ., 2010)$. The problems of low grade semen ejaculates are common predominantly in crossbred bulls and to support the genetic improvement programme there is a need to produce quality semen from genetically superior bulls. This would entail maximum utilization of males through frozen semen technology with high fertility. Proper feeding management of the young bulls becomes more important for production of quality semen. Therefore suitable nutritional and management strategies are being searched for and incorporated so as to maximize quality semen production without discarding too many poor quality ejaculates. Severe undernutrition or over-feeding and deficiency of specific nutrients are the most common causes of impaired reproduction in bulls. Balanced nutrition during pre-weaning and post-weaning stages of male calves has a significant impact on testicular steroidogenesis and gonadotropins releasing hormone which ultimately determine the bull fertility (Singh et al., 2018).

Several reports on the role of micronutrients (Vitamins and minerals) and effect of balanced nutrition with adequate micronutrients in feed and their supplementation on overall health, reproductive performance in male i.e. sperm production, semen quality and fertility are well documented in dairy animals (Smith and Akinbamijo, 2000; McDowell, 2000; Kumar et al., 2010, Bindari et al., 2013, Dahiya et al., 2013; Singh et al., 2018; Pamungkas et al., 2019). Deficiencies of vitamins especially vitamin A leads to impairment of male reproduction i.e. delayed puberty, poor libido, testicular atrophy, degeneration of germinal epithelium, reduced or inhibited spermatogenesis (Schilling et al., 1964,
Maynand et al., 1979 and Ganguly et al., 1980). Role of vitamin $\mathrm{E}$, as an antioxidant in improving semen quality is also well documented (Cooper et al., 1987, Hussain et al., 2018).

Therefore, keeping in view of the importance of nutrients and micronutrients (Vitamin \& minerals) in improving the quality of semen as reported earlier, the present study was planned to improve the semen quality of crossbred cattle bulls with exogenous administration of vitamins.

\section{Materials and Methods}

A group of 8 Crossbred cattle bulls (75\% Holstein Friesian; 25\% Sahiwal, 3-5 years old) maintained at dairy farm GADVASU, Ludhiana apparently healthy showing no visual sign of testicular atrophy and reduced libido but exhibited poor semen quality i.e. (watery ejaculates with poor sperm concentration $<500$ million per $\mathrm{ml}$, Initial sperm motility $<60 \%$ and poor freezability) were undertaken in the present investigation. The bulls were divided into two groups $(n=4$ in each group). Group 1 bulls were given two treatments of multivitamins. In first treatment, Vitamin A (120000 IU); Vitamin $\mathrm{D}_{3}$ (60000 IU); Vitamin E (480 mg); and Nicotinamide (30 mg) and Vitamin H (500 mcg) were administered orally for seven consecutive days (INTAVITA NH oral dose $10 \mathrm{ml}$ INTAS Pharma Limited). After fifteen days of the first treatment the second dose of vitamins viz. Vitamin A (2500000 IU); Vitamin $\mathrm{D}_{3}$ (250000 IU); Vitamin E (1000 IU) was administered through intramuscular route (INTAVITA $10 \mathrm{ml}$, INTAS Pharma Limited). Group II was taken as Control group. Semen collection was suspended during treatment and for at least one month post treatment. Semen was collected with the help of standard artificial vagina method. Various seminal parameters viz. volume (ml), consistency 
(graded as 0-3), mass activity (graded as 0-4), sperm concentration (millions $/ \mathrm{ml}$ ), initial motility (\%), prefreeze motility (\%) and post thaw motility $(\%)$ were recorded before and after treatments. The data was statistically analyzed using $t$ test and compared with control.

\section{Results and Discussion}

The results showed that the mean average values of various seminal parameters volume, consistency, mass activity, sperm concentration and initial motility in control and treated group bulls were $5.21 \pm 0.15,1.29$ $\pm 0.23,1.11 \pm 0.19,337 \pm 30.01,30.03 \pm$ $3.20 ; 5.58 \pm 0.27,2.38 \pm 0.06,3.0 \pm 1.19,870$ \pm 50.76 and $65.61 \pm 1.38$ respectively (Table 1). The values of various seminal parameters obtained in treated group bulls are in agreement with previous studies (Kanchan and Matharoo, 2015; Kanchan and Dubey, 2012). It has been observed in the present study that the bulls seemed apparently healthy showing no visual signs of testicular atrophy, reduced libido and exhibited poor semen quality (Watery ejaculates with poor sperm concentration less than 500 million per $\mathrm{ml}$, initial motility $<60 \%$ ) and did not meet the standards of seminal parameters before treatment. After administration of vitamins AD3E, Nicotinamide and Vitamin $\mathrm{H}$ to crossbred bulls exhibiting poor semen quality, bulls showed marked improvement in semen quality and acquired freezability and values of various seminal parameters meet the standards of semen evaluation and cryopreservation. Similar such improvement in semen quality was reported in mature buffalo breeding bulls given Vitamin AD3 \& $\mathrm{E}$ injections and water splashing at hotter parts of the day (Singh et al., 2001). Similar improvement in semen quality has been also reported after dietary mineral supplementation in AI bulls (Scholz et al., 2012) and mineral-vitamin combining versus herbal supplementation to Ongole crossbred bulls (Pamungkas et al., 2019).

Table.1 Effect of Exogenous Administration of Vitamins on Improving the Semen Quality of Crossbred Cattle Bulls

\begin{tabular}{|l|c|c|c|c|}
\hline Semen parameters & $\begin{array}{c}\text { Standard } \\
\text { values }\end{array}$ & $\begin{array}{c}\text { Before } \\
\text { treatment } \\
(\mathbf{n = 8})\end{array}$ & $\begin{array}{c}\text { Control } \\
(\mathbf{n = 4 )}\end{array}$ & $\begin{array}{c}\text { Treated group } \\
(\mathbf{n = 4 )}\end{array}$ \\
\hline Volume (m) & $4-6$ & $5.18 \pm 0.24$ & $5.21 \pm 0.15$ & $5.58 \pm 0.27$ \\
\hline Consistency (graded as 0-3) & 2.5 & $1.31 \pm 0.21$ & $1.29 \pm 0.23$ & $2.38 \pm 0.06^{*}$ \\
\hline Mass activity (graded as 0-4) & $3-4$ & $1.12 \pm 0.23$ & $1.11 \pm 0.19$ & $3.0 \pm 1.19^{*}$ \\
\hline $\begin{array}{l}\text { Sperm concentration } \\
\text { (millions/ml) }\end{array}$ & $>500$ & $346 \pm 35.86$ & $337 \pm 30.01$ & $870 \pm 50.76^{*}$ \\
\hline Initial motility (\%) & $>65$ & $29.13 \pm 3.23$ & $30.03 \pm 3.20$ & $65.61 \pm 1.38^{*}$ \\
\hline Pre-freeze motility (\%) & $>60$ & Not freezable & Not freezable & $60.66 \pm 1.64$ \\
\hline Post-thaw motility (\%) & $>45$ & Not freezable & Not freezable & $46.33 \pm 0.80$ \\
\hline
\end{tabular}

* indicates values differed significantly $(\mathrm{P} \leq 0.05)$

Micronutrients are involved in such functions as intracellular detoxification of free radicals, synthesis of reproductive steroids and other hormones carbohydrates, proteins and nucleic acid metabolism (Smith and Akinbamijo,
2000). Deficiencies of vitamins leads to severe impairment of male reproduction and classical symptoms of vitamin A deficiency include inhibition of spermatogenesis, reduction in testicular size and decline in 
spermatogenesis (Ganguly et al., 1980), degeneration of testicular epithelium resulting in either reduction or cessation of spermatogenesis (Maynard et al., 1979), delayed puberty and reduced spermatogenesis (Schilling et al., 1964). Effect of vitamin E occurs directly or indirectly on the regulation of intratesticular factors which regulates specific steps of germ cell development (Cooper et al., 1987), Antioxidant role of vitamins especially Vitamin $\mathrm{E}$ is well documented on motility, viability and lipid peroxidation of cattle spermatozoa under oxidative stress (Bansal et al., 2009, Muzafer et al., 2012, Hussain et al., 2018).Vitamin D is supplemented to animals housed indoors and its role in cellular metabolism and calcium absorption is well known.

In the present investigation the poor quality of semen ejaculates observed in crossbred bulls might be due to insufficient or inadequate levels of vitamins in the body and resulted in the marked improvement of the semen quality after exogenous administration of vitamins. It seemed that the dose of vitamins treatment administered for specific period of time to these bulls was sufficient enough to replenish the vitamins deficiency and rectified the nutritional imbalance leading to normal functioning of male reproduction which resulted in production of good quality semen. It is well supported by previous studies focusing on importance of balanced nutrition with adequate levels of micronutrients for proper functioning of male reproduction (Tvrda et al., 2013, Singh et al., 2018, Rao et al., 2013, Kumar et al., 2010, McDowell, 2000).

Therefore it is concluded from the present study that exogenous administration of vitamins was quiet helpful in improving the semen quality of crossbred bulls therefore it is suggested that periodic monitoring of micronutrients supplements in diet in recommended amounts is essential to maintain the semen quality to fulfill the nutritional requirements of various genotypes of crossbred cattle bulls with different adaptabilities for proper functioning of male reproduction to fulfill the semen production target under cattle breeding projects successfully.

In future studies on nutritional inadequacies in terms of quantitative feed intake and qualitative nutrients and micronutrients imbalance for optimum production in farm animals needs to be addressed.

\section{References}

Bansal, A.K., Bilaspuri, G.S. 2009.Antioxidant effect of vitamin $\mathrm{E}$ on motility, viability and lipid peroxidation of cattle spermatozoa under oxidative stress. Animal Science Papers and Reports. 27(1): 5-14.

Bindari, Y.R., Shrestha, S., Srestha, N., and Gaire, T.N. 2013.Effect of nutrition on reproduction - A review. Advances in Applied Science Research. 4(1): 421-429.

Chauhan, F.S., Matharoo, J.S., Takkar, O.P., and Singh, M. 1983. Semen characteristics deep freezing of semen and reproductive performance of crossbred cattle. Indian J. Dairy Sci., 36(1):96-100

Cooper, D.R., Kling, O.R., Carpenter, M.P. 1987. Effect of vitamin $\mathrm{E}$ deficiency on serum concentration of folliclestimulating hormone and testosterone during testicular maturation and degeneration. Endocrinology. 120: 83-90.

Dahiya, S.S. and Singh, P. 2013. Nutritional and other management practices for optimum semen production in buffalo bulls. Buffalo Bulletin. 32(1): 277-284.

Ganguly, J., Rao, M.R.S., Murtby, S.K., Sarad, K. 1980. Systematic mode of action of vitamin A. Vitam. Horm. 38:1.

Hussain, M., Begum, S.S., Kalita, M.K., Ahmed, K.U. and Nath, R. 2018. Additives used in semen preservation in 
animals: a short review. International Journal of Chemical Studies. 6(5): 354361.

Kanchan and Dubey, P.P. 2012. Effect of exotic inheritance on semen parameters and conception rate in crossbred bulls. Crop Improvement (special issue) P 1465-1466. International Conference on suitable Agriculture for Food and Livelihood Security (ICSA 2012). Nov. 27-29, 2012, held at PAU, Ludhiana.

Kanchan and Matharoo, J.S. 2015.Effect of semen colour on seminal characteristics in cattle bulls. Indian J. Anim. Res. 49(1): 146-147.

Kumar, S., Pandey, A.K., Rao, M.M. and Ruzzaque, W.A.A. 2010. Role of $\beta$ carotene/vitamin A in animal reproduction. Veterinary World. 3(5): 236-237.

Maynard, L.A., Loosli, J.K., Hintz, H.F., Warner, R.G. 1979. Reproduction. Animal Nutrition. 16:472. $7^{\text {th }}$ ed McGrawHill, New York.

McDowell, L.R. 2000. Reevaluation of the metabolic essentiality of the vitamins, Review - Asian Australian Journal of Animal Science. 13(1): 115-125.

Muzafer, A.B., Rao, M.M., Sanjay, A., Pandey, A.K., Verma, P.K. and Sultana, M. 2012. Effect of antioxidant supplementation on post thaw sperm characteristics, membrane integrity, migration capability and lipid peroxidation in bull semen. Indian Journal of Animal Sciences. 82(5): 457-460.

Pamungkas, D., Firdaus, F., Affandhy, L. and Luthfi, M. 2019. Mineral-vitamin combining versus herbal supplementation to enhance performance Ongole
Crossbred bull. Earth and Environmental Science. 372(012058). The 1st Animal Science and Food Technology Conference, IOP Conf. Series.

Rao, T.K.S., Kumar, N., Patel, N.B., Chauhan, I. and Chaurasia, S. 2013. Sperm Selection techniques and antioxidant fortification in low grade semen of bulls: Review. Vet. World. 6(8): 579-585.

Schilling, E., Krajnc, A. 1964.Intensive feeding of young bulls and its effect on ejaculate and testes. Zuchtungskunde. 37: 1-16, Animal Breeding Abstract 332317.

Scholz, H., Ahrens, A. 2012. Effects of dietary mineral supplementation on semen quality of AI bulls. Wayamba Journal of Animal Science - ISSN: 578 X: 158-164.

Singh, A.K., Rajak, S.K., Kumar, P., Kerketta, S. and Yogi, R.K. 2018. Nutrition and bull fertility: A review. Journal of Entomology and Zoology Studies. 6(6): 635-643.

Singh, P., Sengupta, B.P. and Tripathi, V.N. 2001.Effect of multiple showering and vitamin supplementation on sexual behaviour, quality and freezability of buffalo bull semen. Asian Australian Journal of Animal Science. 14(2): 184188

Smith, O.B., Akinbamijo, O.O. 2000. Micronutrients and reproduction in farm animals. Animal Reproduction Science. 60-61: 549-560.

Tvrda, E., Sikeli, P., Lukacova, J., Massanyi, P., Lukac, N. 2013. Mineral nutrients and male fertility. Journal of Microbiology, Biotechnology and Food Sciences. 3(1): $1-14$.

\section{How to cite this article:}

Kanchan and Dhindsa, S. S. 2020. Effect of Exogenous Administration of Vitamins on Improving the Semen Quality of Crossbred Cattle Bulls. Int.J.Curr.Microbiol.App.Sci. 9(08): 2077-2081. doi: https://doi.org/10.20546/ijcmas.2020.908.235 